\title{
Simulating the Ideal Body Weight in Human Populations
}

\author{
Md. Abdul Hakim \\ Department of Food Technology and Nutritional Science, Mawlana Bhashani Science and Technology University, Bangladesh
}

Copyright $(2017$ by authors, all rights reserved. Authors agree that this article remains permanently open access under the terms of the Creative Commons Attribution License 4.0 International License

\begin{abstract}
Estimation of ideal body weight in human samples in a fine located geographic level is vital for effective health promotion programmes, provision of better health services and population-specific health planning and management. Lack of nutritional knowledge and information gap on various health and nutritional tools negatively impacts the ability of local and national agencies to manage serious health issues and related risks in the community. A solution to this challenge would be to develop a method that simulates reliable statistics on assessing the ideal body weight of human populations. This paper provides a significant appraisal of the biophysical methodologies for estimating ideal body weight to mitigate health-related problems of populations at geographical limited areas. There is no procedure in this multidisciplinary area in estimating ideal body weights of human samples in health physics and biostatistics. The dietician is often at bay in the route ahead of perfect dieting to hold up nutritional soundness of the sample at a population in a community. The aim of this current study is making a dot over these ongoing perils simulating a biophysical modeling to be used in prescribing a confounding free diet. The study findings are the equations (7), (8) and (9) in different health plight regarding to age groups in human population can be an outstanding mathematical modeling as a dieting tool in nutritional physics applicable to the study on health and nutritional research and in the branch of biostatistics. Also it can be a uniquely functional biophysical modeling in the branch of health pedagogy in nutritional epidemiology.
\end{abstract}

Keywords Health Pedagogy, Ideal Body Weight, Nutritional Physics, Malnutrition, Statistical Simulation, Human Populations

\section{Introduction}

About 2 billion people in the world suffer from various degrees of malnutrition [1, 2]. Malnutrition is an underlying cause of deaths of about 2.6 million children each year-a third of child deaths globally [3, 4]. There are 73.9\%, 63.3\% and 57.9\% overweight populations in North America,
Oceania and Caribbean regions respectively in the world [5, 6].

One in every four of the world's children is stunted and in developing countries this is as high as one in three [7, 8]. Under nutrition accounts for $11 \%$ of the global burden of diseases and is considered the premier risk to health condition [9, 10].

Childhood malnutrition leads to stunted growth and inflamed mortality and morbidity which lower the survival opportunities of adults in their later life [11-13]. About 4 of every 5 malnourished children live in South-East-Asia region accounting some $83 \%$ of their deaths to be liable to mild to moderate malnutrition intensity [14]. These health problems are the giants for the world's population day by day and so health problems are in need of identification to overcome these conditions with a view to meet healthy samples of population in different communities [15-17]. Therefore, the current study is conducted in search of a simple biophysical simulating of ideal body weight to sustain healthy health status shirking the process of malnutrition in the world.

\section{Methodology and Data Sources}

This is a methodological review study to design an effective biophysical technique for simulating ideal body weight of human samples in a population. A wide range of instruments have been collected from the logarithmic biophysical modulator in nutritional physics, Leffler formula in pediatrics, unit bracket method in biological mathematics, definitions and equations on weight and mass in biophysics. These instruments have then undergone on different mathematical tools to simulate a new look in computational physics for estimating ideal body weight of human samples in a population which can be used to curb the health and nutritional problems in worldwide nutritional epidemiology.

\section{Results}

Ideal body weight is initially introduced by Devine in 1974 to allow estimation of drug clearances in obese patients [18]. The ideal weights of human populations are in different 
shape rested with the ages of human samples in different geospatial settings [19-22]. The ideal body weight can be grouped into three sections as (A) ideal body weight of human samples of less than 1 year old, (B) ideal body weight of human samples of $1-10$ years old and (C) ideal body weight of human samples of greater than 10 years old [23-25].

Let consider ${ }_{\mathrm{i}} \mathrm{m}<1 \mathrm{y}$ as the ideal body mass in $\mathrm{kg}$ of less than 1 year old human samples, ${ }_{i} m_{1-10}$ as the ideal body mass in $\mathrm{kg}$ of $1-10$ years old human samples, $s_{\mathrm{m}}$ as the number of months old the human samples and $s_{y}$ as the number of years old the human samples in a population.

So, we get the following equations in biological mathematics as per the Leffler formula [26],

$$
{ }_{\mathrm{i}} \mathrm{m}<1 \mathrm{y}=1 / 2 \mathrm{~S}_{\mathrm{m}}+4
$$

and

$$
{ }_{\mathrm{i}} \mathrm{m}_{1-10 \mathrm{y}}=2 \mathrm{~s}_{\mathrm{y}}+10
$$

Let's move with the logarithmic biophysical modulator [27] to assess the ideal body mass in $\mathrm{kg}$ of greater than 10 years old human samples where $\mathrm{m}_{\mathrm{kg}}$ is considered as body mass in $\mathrm{kg}, \mathrm{h}_{\mathrm{cm}}$ as body height in $\mathrm{cm}$ and $\mathrm{H}$ as modulator of health status,

$$
\mathrm{H}=\log ^{-1}\left(4+\log \mathrm{m}_{\mathrm{kg}}-2 \log \mathrm{h}_{\mathrm{cm}}\right)
$$

We can get the ideal body mass using the value of $\mathrm{H}$ as 18 to 25 in equation (3) as per the WHO's BMI classification [28]. So, we get the following equation where ${ }_{\mathrm{i}} \mathrm{m}>10 \mathrm{y}$ is considered as the ideal body mass in $\mathrm{kg}$ of greater than 10 years old human samples in a population,

$$
1 / 8 \int_{18}{ }^{25} \mathrm{H} \mathrm{dH}=\log ^{-1}\left(4+\log \mathrm{m}_{>10 \mathrm{y}}-2 \log \mathrm{h}_{\mathrm{cm}}\right)
$$

We get the following equation solving the integral problem [29] in equation (4),

$$
\begin{gathered}
1 / 8\left[\mathrm{H}^{2} / 2\right]_{18}{ }^{25}=\log ^{-1}\left(4+\log _{\mathrm{i}} \mathrm{m}_{>10 \mathrm{y}}-2 \log \mathrm{h}_{\mathrm{cm}}\right) \\
\text { Or, } 1 / 8\left[25^{2} / 2-18^{2} / 2\right]=\log ^{-1}\left(4+\log _{\mathrm{i}} \mathrm{m}_{>10 \mathrm{y}}-2 \log \mathrm{h}_{\mathrm{cm}}\right) \\
\text { Or, } 1 / 8 \times 150.5=\log ^{-1}\left(4+\log _{\mathrm{i}} \mathrm{m}_{>10 \mathrm{y}}-2 \log \mathrm{h}_{\mathrm{cm}}\right) \\
\text { Or, } 18.8125=\log ^{-1}\left(4+\log _{\mathrm{i}} \mathrm{m}_{>10 \mathrm{y}}-2 \log \mathrm{h}_{\mathrm{cm}}\right)
\end{gathered}
$$

Taking $\log$ [30] in both side of equation (5),

$$
\begin{gathered}
\log 18.8125=4+\log _{\mathrm{i}} \mathrm{m}_{>10 \mathrm{y}}-2 \log \mathrm{h}_{\mathrm{cm}} \\
\text { Or, } 1.27=4+\log _{\mathrm{i}} \mathrm{m}_{>10 \mathrm{y}}-2 \log \mathrm{h}_{\mathrm{cm}} \\
\text { Or, } \log { }_{\mathrm{i}} \mathrm{m}_{>10 \mathrm{y}}=2 \log \mathrm{h}_{\mathrm{cm}}-4+1.27 \\
\text { Or, } \log { }_{\mathrm{i}} \mathrm{m}_{>10 \mathrm{y}}=2 \log \mathrm{h}_{\mathrm{cm}}-2.73 \\
\text { Or, }{ }_{\mathrm{i}} \mathrm{m}_{>10 \mathrm{y}}=\log ^{-1}\left(2 \log \mathrm{h}_{\mathrm{cm}}-2.73\right)
\end{gathered}
$$

The body weight is mathematically the product of body mass and the magnitude of gravitational acceleration $g$ [31, 32]. Therefore, the ideal body weights of human samples in a population are on the following gesture whereas ${ }_{\mathrm{i}} \mathrm{W}_{<1 \mathrm{y}}, \mathrm{W}_{1-}$ $10 \mathrm{y}$ and ${ }_{\mathrm{i}} \mathrm{W}>10 \mathrm{y}$ considerable as ideal body weight in Newton of less than 1 year old human samples, ideal body weight in Newton of $1-10$ years old human samples and ideal body weight in Newton of greater than 10 year old human samples respectively in a population.

$$
\begin{gathered}
{ }_{\mathrm{i}} \mathrm{W}_{<1 \mathrm{y}}=\left[{ }_{\mathrm{i}} \mathrm{m}<1 \mathrm{y}\right] \mathrm{g} \\
{ }_{\mathrm{i}} \mathrm{W}_{1-10 \mathrm{y}}=\left[{ }_{\mathrm{i}} \mathrm{m}_{1-10 \mathrm{y}}\right] \mathrm{g} \\
{ }_{\mathrm{i}} \mathrm{W}>10 \mathrm{y}=\left[{ }_{\mathrm{i}} \mathrm{m}>10 \mathrm{y}\right] \mathrm{g}
\end{gathered}
$$

\section{Discussion}

Simulation reproduces the behavior of a system using a mathematical model. Simulations have become a useful tool for the mathematical modeling of many natural systems in physics, astrophysics, climatology, chemistry and biology, human systems in economics, psychology, social science and engineering. It can be used to explore and gain new insights into the new technology and to estimate the performance of systems too complex for analytical solutions [33]. This study can introduce an anew simulation modeling in the branch of nutritional physics in simulating ideal body weight of human samples in different populations [34-38] for sustaining healthy population status in different countries. There is big confusion on using body mass or body weight as mass is a scalar quantity of unit meter while the weight is a vector quantity containing the unit Newton. The purpose of this study is to simulate the way to get ideal body weight in unit Newton as there is no methodological issue of getting ideal body weight in unit Newton according to the proper definition of weight in pure and applied physics. It is tried to represent weight accordingly as it is an ideal indicator or health status in human samples in a community [39-41]. The study results can take a new turn in simulating ideal body weight of human populations evading all the previous faulty procedures [42-45]. This biophysical simulation can be a spatial health micro simulation modeling constructive to design effective policies and see the governments and NGOs, environmental and spatial effects across different countries to bear up against the health and nutritional perils to make sure for ending malnutrition by 2020 [46-53]. This health micro simulation modeling [equation (7), (8) and (9)] can be a super active tool in health pedagogy [54-59] to resist nutritional victimization through using nutrition counseling in nutritional epidemiology in the branch of health science and biostatistics [60-63].

\section{Conclusions}

Malnutrition is one of the bold public health panics in both the developing and developed countries. The current study outcomes are the three biophysical equations to simulate ideal body weights branding ${ }_{\mathrm{i}} \mathrm{W}_{<1 \mathrm{y}},{ }_{\mathrm{i}} \mathrm{W}_{1-10 \mathrm{y}}$ and ${ }_{\mathrm{i}} \mathrm{W}>10 \mathrm{y}$ applying the equation (7), (8) and (9) in biological mathematics. The national and international big bugs should popularize this health and nutritional simulation to reduce malnutrition bulk as degree as possible. Future research should adopt this cozy biophysical simulation modeling in health pedagogy. This simulation modeling should also be explored in further study for policy designing, analysis and 
checking spatial effects for childhood, adulthood and geriatric health and nutritional condition upgradation.

\section{REFERENCES}

[1] Rahman A, Chowdhury S, Karim A. and Ahmed S. Factors associated with nutritional status of children in Bangladesh: a multivariate analysis. Demogr India 2008; 37(1): 95-109.

[2] Rahman A. Significant risk factors for childhood malnutrition: evidence from an Asian developing country. Sci. J Public Health 2016; 4 (1-1): 16-27.

[3] Chowdhury MR, Rahman MS, Khan MM, Mondal MN, Rahman MM and Billah B. Risk factors for child malnutrition in Bangladesh: A multilevel analysis of a nationwide population-based survey. J Pediatr 2016; 172: 194-201.

[4] Rahman A and Hakim MA. An epidemiological study on hygiene practice and malnutrition prevalence of beggars children in Bangladesh. Int. J. Nutr. Diet. 2016; 4 (1): 29-46.

[5] Walpole SC, Prieto-Merino D, Edwards P, Cleland J, Stevens $G$, Roberts I et al. The weight of nations: an estimation of adult human biomass. BMC Public Health 2012, 12 (1): 439.

[6] Hakim MA and Rahman A. Health and nutritional condition of street children of Dhaka city: an empirical study in Bangladesh. Sci. J. Public Health 2016; 4 (1-1) 6-9.

[7] Megabiaw B and Rahman A. Prevalence and determinants of chronic malnutrition among under-5 children in Ethiopia. Int. J. Child Health Nutr. 2013; 2(3): 230-236.

[8] de Onis $\mathrm{M}$, Blossne $\mathrm{M}$ and Eorghi E. Prevalence of stunting among pre-school children 1990-2020', Growth Assessment and Surveillance Unit. Public Health Nutr. 2011; 14:1-7.

[9] Hakim MA, Talukder MJ and Islam MS. Nutritional status and hygiene behavior of government primary school kids in central Bangladesh. Sci. J. Public Health 2015; 3(5): 638-642.

[10] Black RE, Allen LH and Bhutta ZA, Caulfield LE, de Onis M, Ezzati M, Mathers C and Rivera J. Maternal and child undernutrition: global and regional exposures and health consequences. The Lancet 2008; 371(9608): 243-60.

[11] Rahman A and Chowdhury S. Determinants of chronic malnutrition among preschool children in Bangladesh. $J$ Biosoc Sci. 2007; 39(2): 161-173.

[12] Rahman A, Chowdhury S and Hossain D. Acute malnutrition in Bangladeshi children: levels and determinants. Asia Pac J. Public Health 2009; 21 (1): 294-302.

[13] Rahman A and Hakim MA. Malnutrition prevalence and health practices of homeless children: a cross-sectional study in Bangladesh. Sci. J. Public Health 2016; 4 (1-1): 10-15.

[14] United Nations International Children's Emergency Fund (UNICEF). Malnutrition in South Asia: a regional profile, UNICEF report, 1997; p8.

[15] Rahman A and Kuddus A. A new model to study on physical behaviour among susceptible infective removal population. Far East J. Theor Stat 2014; 46(2): 115-135.
[16] Hakim MA and Kamruzzaman M. The dance of poverty and education for childhood nutritional victimization in Bangladesh. J Biol. Env. Eng. 2016; 1 (1): 6-9.

[17] Rahman A, Harding A, Tanton R and Liu S. Simulating the characteristics of populations at the small area level: new validation techniques for a spatial microsimulation model in Australia. Comput. Stat. Data Analys. 2013; 57(1): 149-165.

[18] Devin BJ. Gentamicin therapy. Drug Intell Clin Pharm 1974; 8 (11): $650-5$

[19] Perreau-Lenz S, Pévet P, Buijs RM and Kalsbeek A. The biological clock: the bodyguard of temporal homeostasis. Chronobiol Int 2004; 21:1-25.

[20] Speakman JR and Westerterp KR. Associations between energy demands, physical activity and body composition in adult humans between 18 and 96 y of age. Am J Clin Nutr 2010; 92 (4): 826-834

[21] Rahman A. Estimating small area health related characteristics of populations: a methodological review. Geospat Health 2017; 12 (1): 3-14.

[22] Rahman A and Harding A. Prevalence of overweight and obesity epidemic in Australia: some causes and consequences. JP J Biostat 2013; 10 (1): 31-48.

[23] So TY, Farrington E and Absher RK. Evaluation of the accuracy of different methods used to estimate weights in the pediatric population. Pediatr 2009; 123 (6): e1045-51.

[24] Chow CC and Hall KD. The dynamics of human body weight change. PLoS Comput Biol 2008; 4(3): e1000045.

[25] Kozusko F. Body weight setpoint, metabolic adaption and human starvation. Bull Math Biol 2001; 63 (2): 393-403.

[26] Pai MP and Paloucek FP. The origin of the ideal body weight equations. Ann Pharmacotherapy 2000; 34 (9): 1066-1069.

[27] Rahman A and Hakim MA. Modeling health status using the logarithmic biophysical modulator. J Public Health Epidemiol 2017; 9 (5): 145-50.

[28] World Health Organization (WHO). BMI Classification. Global Database on Body Mass Index 2006.

[29] Broach D. Integration of clinical research documentation in electronic health records. Comput Inform Nurs 2015; 33 (4): 142-9.

[30] Pierce RC. A brief history of logarithm. Two-Year Coll Math J 1977; 8 (1): 22-6.

[31] Galili I. Weight and gravity teachers' ambiguity and students' confusion about the concepts. Int J Sci Eeduc 1993; 15 (2): 149-62.

[32] Galili I and Lehavi Y. The importance of weightlessness and tides in teaching gravitation. Am J Phys 2003; 71 (11): 1127-35.

[33] Strogatz S. The end of insights. In Brockman J. What is your dangerous idea? Harper Collins 2007.

[34] McHugh G S, Butcher I, Steyerberg E W, Marmarou A, Lu J, Lingsma H F, Weir J, Maas A I and Murray G D. A simulation study evaluating approaches to the analysis of ordinal outcome data in randomized controlled trials in traumatic brain injury: results from the IMPACT project. Clin Trials 2010; 7 (1): 
44-57.

[35] Rahman A and Harding A. Some health related issues in Australia and methodologies for estimating small area health related characteristics. Online Working Paper Series2010; WP-15, NATSEM, University of Canberra. p. 1-59.

[36] Rahman A and Hakim MA. Measuring modified mass energy equivalence in nutritional epidemiology: a proposal to adapt the biophysical modelling approach. Int J Stat Med Res 2016; 5 (3): 219-223.

[37] Hakim MA. Biophysical modeling of cellular energy in human dietetics: an appraisal in nutritional physics and cell biology. Am J Food Sci Nutr Res 2017; 4 (4): 125-129.

[38] Rahman A. Small area estimation through spatial microsimulation models: Some methodological issues, Paper presented at the $2^{\text {nd }}$ General Conference of the International Microsimulation Association, The National Conference Centre Ottawa, Canada, 2009; p. 1- 45 (June 8 to 10).

[39] Hakim M A. Modeling food energy in bioenergetics. $J$ Adv Med Pharm Sci 2017; 14 (4): 1-7.

[40] Rahman A, Hakim MA,Hanif MA, Islam MR and Kamruzzaman M. Dietary practices, health status and hygiene observance of slum kids: a pilot study in an Asian developing country. JP J Biostat 2016; 13 (2): 195-208.

[41] Hakim MA. Biophysical modeling of dietary energy in biochemical modeling. Am J Appl Indust Chem 2017; 3 (2): 5-9.

[42] Robinson M R et al. Population genetic differentiation of height and body mass index across Europe. Nature Genetics 2015; 47: 1357-1362.

[43] Jequier E and Tappy L. Regulation of body weight in humans. Physiol Rev 1999; 79(2): 451-480.

[44] Thomas D M et al. A mathematical model of weight change with adaptation. Math Biosci Eng 2009; 6 (4): 873-87.

[45] Sheiner L B. Learning versus confirming in clinical drug development. Clin Pharmacol Ther1997; 61:275-291.

[46] Brinkman S A, Gialamas A, Rahman A et al. Jurisdictional, socioeconomic and gender inequalities in child health and development: Analysis of a national census of 5 year olds in Australia. BMJ Open 2012; 2(5): 1-15.

[47] Mould DR and Frame B. Population pharmacokinetic-pharmacodynamic modeling of biological agents: when modeling meets reality. J Clin Pharmacol 2010; 50:91S-100S.

[48] Huang SM, Abernethy DR, Wang Y, Zhao P and Zineh I. The utility of modeling and simulation in drug development and regulatory review. J Pharm Sci2013; 102: 2912-2923.

[49] Rahman A, Harding A, Tanton R and Liu S. Methodological issues in spatial microsimulation modelling for small area estimations. Int J Microsimul 2010; 3(2): 3-22.

[50] Hakim MA. Mathematical Modeling of Energy Balancing for Diet Planning in Nutritional Physics. Int J Nutr Diet 2017; 5 (1): 29-41.

[51] Lubitz D, Seidel J S, Chameides L, Luten R C, Zaritsky A L and Campbell F W. A rapid method for estimating weight and resuscitation drug dosages from length in the pediatric age group. Ann Emerg Med 1988; 17 (6): 576-81.

[52] Mould D R and Upton R N. Basic concepts in population modeling, simulation, and model-based drug development-part 2: introduction to pharmacokinetic modeling methods. CPT Pharmacometrics Syst Pharmacol2013; 2:e38.

[53] Song B and Thomas D M. Dynamics of starvation in humans. J Math Biol 2007; 54 (1): 27-43.

[54] Hall K D. Mathematical modelling of energy expenditure during tissue deposition. Br J Nutr 2010; 104: 4-7.

[55] Gortmaker S L, Swinburn B A, Levy D et al. Changing the future of obesity: science, policy and action. Lancet 2011; 378 : 838-47.

[56] Garrow J S, Stalley S, Diethelm R, Pittet P, Hesp R and Halliday D. A new method for measuring the body density of obese adults. Br J Nutr 1979; 42(2) 173-83.

[57] Poole S A, Hart C N, Jelalian E and Raynor H A. Relationship between dietary energy and dietary quality in overweight young children: a cross-sectional analysis. Pediatr Obesity 2016; 11(2): 128-135.

[58] Hakim M A and Islam M S. Elementary of food science and technology ( $1^{\text {st }}$ Edition) [ISBN 984-658-612-6], 2016; p. 37.

[59] Karsten K. Educational theory as tropical rheotic: The concepts of pedagogy of Johann Freidrich Herbert and Freidrich Schleiermacher. Stud Phil Educ 2012; 31(1): 265-273.

[60] Kamruzzaman M and Hakim M A. Basic rights on the wane, human rights on brown study: a case study on thrown away children in Bangladesh. Int J Env Plan Manage 2016; 2 (4): 29-35.

[61] Hakim M A. Malnutrition prevalence and nutrition counseling in developing countries: a case study. Int J Nurs Health Sci 2016; 3 (3): 19-22.

[62] Kamruzzaman $M$ and Hakim M A. Food and nutrition counseling in Bangladesh: a NC4HD approach in health statistics. Am J Biol Chem 2017, 5 (1): 1-5.

[63] Rahman A. Risk factors for malnutrition in Bangladeshi children, paper presentation at the Showcasing Toowoomba Area Health Research conference (STAHR-06), Centre for Rural and Remote Area Health, University of Southern Queensland, Toowoomba 2006. 